\title{
New risk assessment tools in The Netherlands
}

\author{
Heleen de Kraker ${ }^{*}$ and Marjolein Douwes \\ TNO, P.O. Box 718, 2130 AS Hoofddorp, The Netherlands
}

\begin{abstract}
In this paper an introduction to and description of the risk assessment tools that are freely available for companies in The Netherlands is given. It is explained in what way the tools can and should be used and how the level I checklist for physical load and the level II instruments are related. The two instruments that -in 2011- made this 'Dutch toolbox' complete, are the checklist physical load and the Working Posture Risk Assessment Tool (WRAP 1.0). The content, the development process and some examples of these tools are explained. The toolbox is complete but does need additional evaluation to improve the quality of the assessments and the usability in practice.
\end{abstract}

Keywords: risk assessment, MSD, practical tools, physical load at work

\section{Introduction}

Musculoskeletal disorders (MSD) are still a major cause of sick leave in the Dutch working population. Back problems (15\%) and arm, neck and shoulder problems (12\%) are the most common, but problems with legs, knees and hips are also responsible for as much as ten percent [2] of the total number of sick leave days. Causes are not only found in 'high load jobs' such as lifting, pushing and pulling, but can also be found in VDU work or working postures. Companies in The Netherlands are obligated to protect their employers from health and safety risks such as risks due to physical load at work.

To accommodate Dutch companies in this obligation, the Ministry of Social Affairs and Employment provides them with freely available risk assessment tools. Companies can use these tools to assess possible risks. When the resulting risks from the assessment are known, adequate measures and solutions can be developed and implemented. This will increase the chance of successful interventions and may eventually prevent the occurrence of MSD complaints.

In 2007 it was concluded that an easy to apply method to determine risks of developing disorders or complaints in arm, neck or shoulder in hand-arm tasks was lacking in The Netherlands. The Ministry of Social Affairs and Employment therefore asked TNO to develop a tool that employers can use to determine the risks of 'hand-arm tasks'. In 2009, a similar development was initiated to assess risks of developing MSD's due to working postures.

Finally, it appeared that companies had a need for a 'level I' checklist physical load that enabled them to quickly assess all aspects of physical load. The results of this checklist should give a first indication of possible risks and also show for which aspects a level II (follow-up) assessment should be done.

Potential users of the checklist are those who are responsible for a company's working conditions, such as prevention officers, working conditions coordinators, personnel officers, HRM staff or - in small companies - the director himself. Health and safety experts and working conditions services are also encouraged to use the methods. The methods do not require any specific prior knowledge or special training.

In 2011, the complete set of instruments has been made freely available in The Netherlands (the Hand Arm Risk assessment Method (HARM 1.0) is available since 2009). This paper describes the different items and structure of the level I checklist, and the relation between the checklist and the level II follow-

*Corresponding author. Email: heleen.dekraker@tno.nl 
up instruments. Special attention will also be paid to the newly developed level II assessment tool for working postures.

\section{Structure: level I and II instruments}

\subsection{Level I checklist}

The major goal of the level I checklist was to develop a quick assessment tool for all aspects of physical load at work. The need for such a tool was a result from an evaluation of HARM (level II) that showed that the use of the method was quite complex in practice (especially within SME's). This raised the need to develop an easy and quick checklist which can give the confirmation that HARM (or other level II assessment tools) really need to be applied.

Moreover, a freely available checklist covering all aspects of physical load was lacking in The Netherlands.

The 'level I' checklist consists of nine steps (comparable to the structure in steps in HARM) and is to be used on task-level. The questions to be answered in each step are however much easier and consist of 'yes' and 'no' answer categories. The aspects of physical load in the checklist are listed in table 1.

For assessing a task, the user needs to answer the questions in all steps. If certain aspects are not relevant for the task, the more detailed questions on this aspect will be omitted. For example, if the question: "Are work tasks performed in which especially arms and hands are active while legs and body are inactive, for at least 30 minutes a day?" is answered with 'no', the more detailed questions on hand-arm tasks will not appear and do not need to be filled out. If aspects are relevant for the assessed task, the user is requested to fill in the more detailed questions.

Table 1

Aspects of physical load in the checklist, per step.

\begin{tabular}{|cl|}
\hline $\begin{array}{c}\text { Step in } \\
\text { checklist }\end{array}$ & \multicolumn{1}{c|}{ Aspect of physical load } \\
\hline 1 & lifting and carrying \\
\hline 2 & pushing and pulling \\
\hline 3 & hand- arm tasks \\
\hline 4 & working postures \\
\hline 5 & computer work \\
\hline 6 & vibrations (hand arm and whole body) \\
\hline 7 & energetic over load \\
\hline 8 & energetic under load \\
\hline 9 & presence of work related complaints \\
\hline
\end{tabular}

After answering all questions, the results will be given per step. For each aspect of physical load a traffic light shows if a possible risk is present; the traffic light is green if the task poses no increased risk, the traffic light is red when the task possibly poses an increased risk of musculoskeletal pain. In case of a red traffic light, the use of a specific level II assessment tool is recommended. The results never show an amber light (see also 3.1). In case of a red light, a specific level II assessment tool (and link to this tool) is recommended for most steps. Obviously, the user can also decide to use another tool, for example a sector specific or previously used tool.

\begin{tabular}{|c|c|c|}
\hline \multicolumn{2}{|r|}{ Level I } & Level II \\
\hline \multirow{10}{*}{$\begin{array}{l}\text { checklist } \\
\text { physical } \\
\text { load }\end{array}$} & aspects in checklist: & follow up instruments: \\
\hline & lifting and carrying & $\longrightarrow$ NIOSH (lift) and KIM (carrying) \\
\hline & pushing and pulling & $\longrightarrow$ KIM pushing/ pulling \\
\hline & hand- arm tasks & $\longrightarrow$ HARM \\
\hline & working postures & $\longrightarrow$ WRAP \\
\hline & work with display units & $\longrightarrow$ checklist VDU work (in Dutch) \\
\hline & vibrations (hand arm and whole body) & $\longrightarrow$ Vibration Calculators HSE \\
\hline & energetic over load & $\longrightarrow$ no follow up tool, advice in text \\
\hline & energetic under load & $\longrightarrow$ no follow up tool, advice in text \\
\hline & presence of physical complaints & $\longrightarrow$ no follow up tool, advice in text \\
\hline
\end{tabular}

Fig. 1. The structure of the assessment process: companies start by applying the checklist. If this results in a red traffic light, a risk might be present and a level II assessment should be done. For green lights the level II assessment is not required. If a specific risk is presumed, employers can also directly perform a level II assessment (without applying the checklist first). 


\subsection{Level II instruments}

In order to resolve the 'red aspects', the user is recommended to apply a level II assessment tool.

The suggested tools in the checklist are selected based on free availability in Dutch and the tools had to be relatively well-known (and commonly used). If there were no tools available, meeting these criteria, a suggested follow up advice is given in text (for example, this is the case for energetic over- and under load). The level II instruments are shown in figure 1. For hand arm-tasks we used our previously developed HARM $[1,3]$. For working postures we implemented a newly developed method. More details on this development can be read in section 4 .

\section{Checklist development}

The main goal of developing the checklist was to meet the companies need for a 'level I' checklist with which a quick assessment of all aspects of physical load can be performed. The checklist should be quick and easy in use and give a first indication of possible risks.

\subsection{Development steps and choices}

The first step in the development was to investigate whether level I checklists already exist and to what extent level II instruments are appropriate as follow-up instruments. No complete checklists, combining all aspects of physical load were found, so we decided to develop a new checklist. Moreover, the questions in the checklist had to be phrased in such a way that they covered the most important risks and that they were in line with the level II methods. Basically, the checklist questions are simplifications of the questions in the follow up instruments. In order to really keep the questions easy and quick to answer, we strongly preferred questions that could be answered by a simple 'yes' or 'no'.

Furthermore, it was decided to use a 'green-red'traffic light. Reason for omitting the amber light was a combination of underlying goals of the checklist and the low distinctive power. Users of the checklist are believed to be primarily interested in a first indication of possible risks and the necessity to perform level II assessments. Regarding this goal, green would mean no additional assessment, amber and red would mean a need for additional assessment(s). The second reason is based on practical considerations; the distinctive power between the three categories (green- amber-red) is reduced due to the simplification in questions. Therefore it is more reliable to use only two categories. The threshold between green and red was chosen in an expert group in which 'greenish-amber' was put into the green category and 'reddish-amber' into the red category. The main criteria for these decisions were somewhat contradictory: the checklist had to be protective for workers and thus to be able to detect risks (reddish-ambers). On the other hand, another main purpose of the checklist is to make the assessment process easier and more effective for companies. Consequently, the checklist should not be 'too protective' in suggesting a level II assessment for risks that are 'barely amber'. If the checklist would suggest level II assessments in almost all the cases, it would be an extra time investment (instead of lowering the burden on companies).

After developing the first version of the checklist and thresholds, tests were done comparing the results of the checklist with the corresponding level II instruments (for five to ten tasks per aspect). Based on the results of this comparison, the checklist was adjusted.

\subsection{Examples of checklist application}

First example: step 3 for hairdresser cutting hair

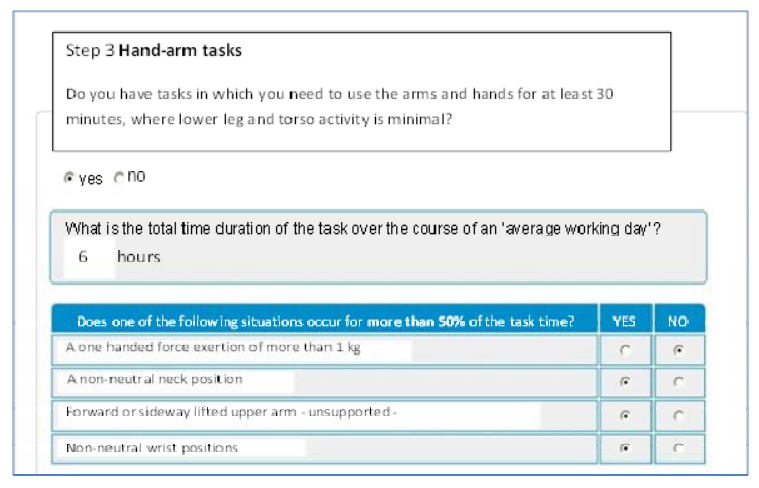

Fig. 2. Screenshot of step 3, hand-arm tasks for hairdresser cutting hair. Actual cutting is performed for 6 hours during a regular day.

The result of the given answers above in the checklist would be a red traffic light with the accompanying advice to perform a level II assessment (applying HARM). This result is quite well comparable with the HARM score of this task: 47 (so called 'reddish-amber'). 
Second example: output of step 8 , energetic under load:

No suitable level II instrument is available for step 8, energetic under load. If the result for this step is a red light, the advice is given in text. For energetic under load this would be: "To interrupt the static load in the neck- shoulder region, you should take 7,5 minute break every 1,5 hour in the morning and a 10 minute break in the afternoon. During these breaks the muscles with the static load should either relax or have a dynamic load."

\section{WRAP development}

The main goal of the development was to offer a new instrument for employers to assess risks of working postures. Reason for this new development was a lack of a tool for risk assessment of working postures in The Netherlands and the limited role of duration in the existing tools. The instrument should cover postures of the head, trunk, upper and lower extremities and should be quick and easy to apply (i.e. does not require any specific prior knowledge or special training).

\subsection{Development steps and choices}

The development started with a literature review on risk factors (body angles), time factors (duration, frequencies and recovery times of risk factors) and assessment factors (thresholds, relative weights, scoring). Already existing methods and experimental literature were also consulted. Very few results on time factors and recovery times, were found in literature. Moreover, results were sometimes difficult to compare because studies used different angles and durations. Because the literature review did not pro-

Time factors used for risk assessment per postural risk factor.

\begin{tabular}{|c|c|c|c|c|}
\hline \multirow[b]{2}{*}{ Step $^{1}$} & \multirow[b]{2}{*}{ Postural risk factors } & \multicolumn{3}{|c|}{ Risk assessment made based on questions on: } \\
\hline & & $\begin{array}{l}\text { total duration } \\
\text { per day }\end{array}$ & $\begin{array}{l}\text { continuous } \\
\text { duration }\end{array}$ & $\begin{array}{l}\text { nature of the load: } \\
\text { static/ dynamic }\end{array}$ \\
\hline 2 & $\begin{array}{l}\text { working in kneeled, squatting and } \\
\text { standing positions }\end{array}$ & $\mathbf{x}$ & $\mathbf{x}$ & \\
\hline 3 & awkward and twisted positions of trunk & $\mathbf{x}$ & & $\mathbf{x}$ \\
\hline 4 & neck bending and neck rotation & $\mathbf{x}$ & & \\
\hline 5 & upper arm elevation & $\mathbf{x}$ & & \\
\hline 6 & wrist positions and extreme positions & $\mathbf{x}$ & & $\mathbf{x}$ \\
\hline
\end{tabular}

\footnotetext{
${ }^{1}$ Step 1 , in which the task definition and task duration are defined, is not included in this table.
}

vide a thorough basis for further development, an expert session was organized to fill in the gaps in knowledge. In this consensus meeting, the thresholds were as much as possible chosen based on the literature but the practical usability was also considered, i.e. the descriptions of the threshold body angles should be unambiguous, easy to understand and observable for all users.

After the literature review and expert session, the risk factors in the second column of table 2 were included in the first version of the tool.

For each risk factor it was determined which time factors need to be known in order to assess the risks. In the last three columns of table 2, the different time factors for each assessment are given. For all risk factors the total time per day is needed for the assessment. For some factors the continuous (uninterrupted) duration or the nature of postural load (static/ dynamic load) is asked additionally. These durations are given in categories and are specific to the risk factor. For example, the cut off point for the durations of trunk flexion (60 minutes and 4 hours) are higher than the durations of working in squatted position (30 and 60 minutes). All postures are described in text and illustrated by photographs. For postures that are expected to occur with a high frequency a help form can be consulted, with which the user, step by step, is guided to calculate the total duration.

A first test with six users in six different companies was performed. The results showed a good practical usability and the users found the output relevant, usable and clear. Some textual adjustments were made based on these test results. 


\subsection{Example of work WRAP application}

The screenshot in figure 3 shows one of the steps. For the position shown, the user needs to indicate the continuous and total duration per day that the workers work in this position. The total duration is the sum of all the (shorter) periods that this position is observed. In case certain positions are very frequently performed in a short period of time, the use of a help-form is advised. This form enables you to estimate the short durations and their frequencies more precisely as well as to estimate the total duration.

In figure 4 a screenshot of step 7, overview of the results can be seen. For each category (green, amber, red) the postures with that score are given. In the current example a seriously increased risk is present for working in a standing position, upper arm elevation and wrist positions.
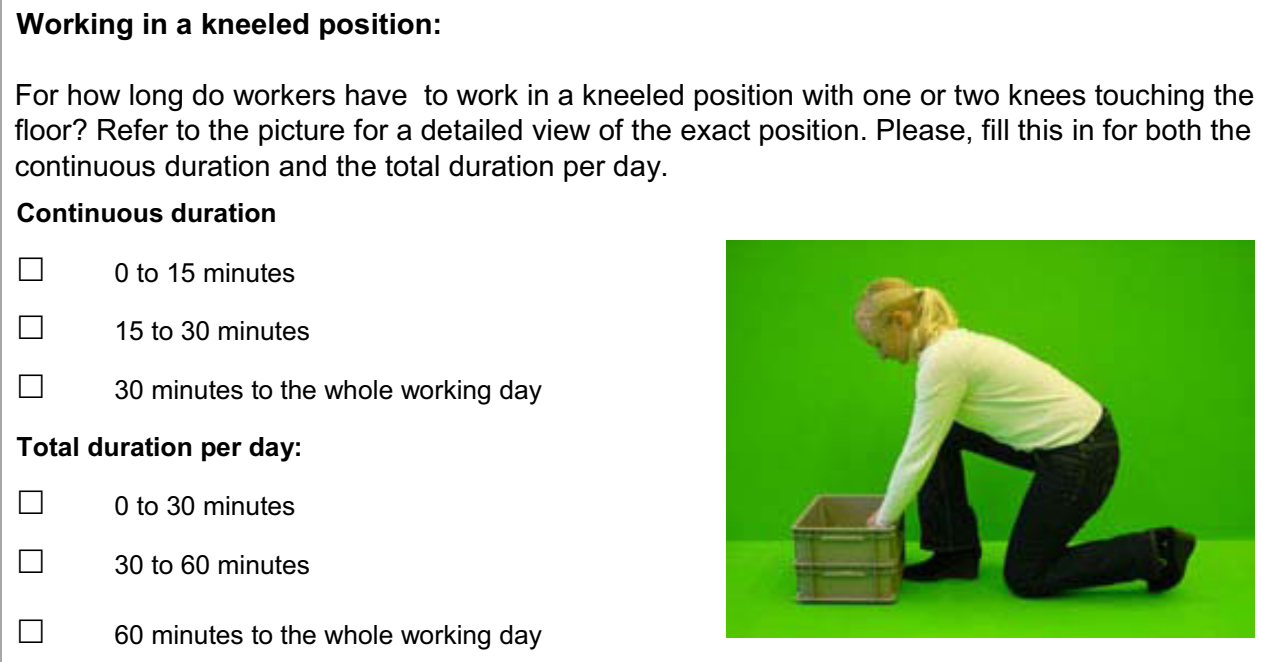

Fig. 3. Screenshot of step2: working in a kneeled position. The user has to indicate the continuous duration and the total time per day that the presented postures occurs. 


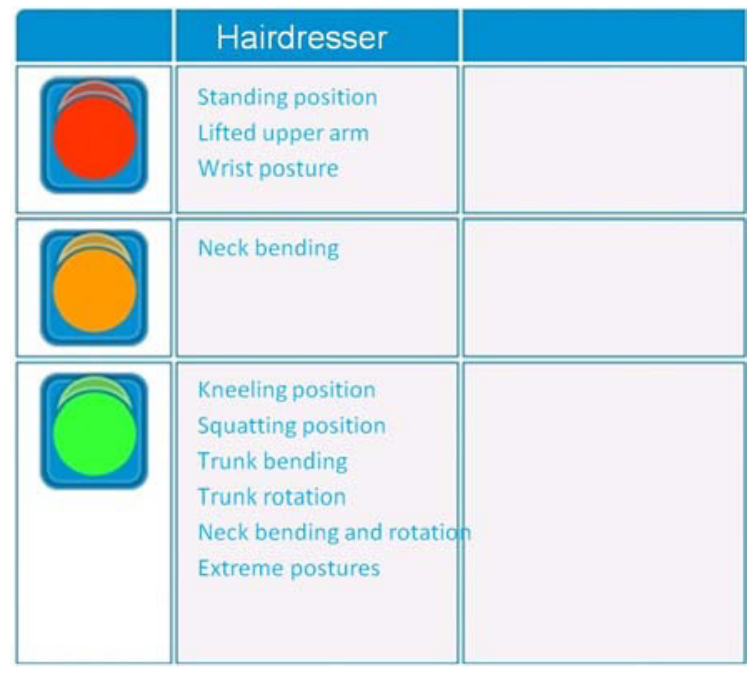

Fig. 4. Screenshot of step 7, the overview of results. For each category (green, amber, red) the postures with that score are given.

\section{Current and future activities}

\subsection{General}

A current (and ongoing) activity is the implementation and stimulation of the usage of the tools. This activity will especially be done for the level I checklist, and the level II HARM and WRAP. The main goal is to introduce the methods to the target group and stimulate its use. Several communication methods will be used, e.g. distribution of flyers and organizing presentations and workshops on the methods. The long term goals are better risk assessments, an increase of interventions to reduce the risks and subsequently a decrease in musculoskeletal complaints.

\subsection{Checklist and WRAP}

The checklist and WRAP were tested with a small number of tasks. More thorough tests, with greater variety of tasks and users will be performed to improve the quality of the assessments. Moreover, the practical usability (does it meet its goals: is the checklist really easy and does it lead to a more efficient risk assessment process?) and user friendliness should also be evaluated.

Since one of the conclusions from the literature review on postures was a lack of knowledge on time and recovery aspects, it was decided to initiate a study in which time aspects will be studied in more detail. $\mathrm{A} \mathrm{PhD}$ study on the duration and recovery aspects of postural load will be performed. This project will eventually lead to a more complete and scientifically based WRAP 2.0.

\section{References}

[1] Douwes M, Kraker H. de, Hand Arm Risk assessment Method (HARM), a new practical tool. $17^{\text {th }}$ world congress on Ergonomics, August 9-14, Beijing, 2009

[2] Hooftman, W., Klein Hesselink, J., van Genabeek, J., Wiezer, N. and Willems D., 2011. Arbobalans 2010, Kwaliteit van de arbeid, effecten en maatregelen in Nederland . TNO-report (in Dutch), Hoofddorp, The Netherlands

[3] Kraker H. de, Douwes M. The development of a practical tool for risk assessment of manual work - the 'HAT-tool', 40th Annual Conference of the Nordic Ergonomics Society, Iceland, 2008 